patients taking triazolam had more impairment of memory than the others. ${ }^{10}$

Bixler and colleagues have described a different, more worrying form of amnesic effect: the period of impaired recall included events occurring the day after ingestion of the drug (rather than just before or during the sleep period). ${ }^{12}$ Five of six patients in the group treated with triazolam reported subjective memory impairment, yet one of these same patients reported a single episode during the placebo phase. Also, the group treated with triazolam, but not the group treated with temazepam, displayed an objectively impaired ability to recall tasks performed the morning after they took the drug.

The greatest controversy concerns the association of triazolam with psychiatric disturbances during the course of treatment, which was first suggested by anecdotal reports. Subsequently in a double blind study Morgan and Oswald reported that treatment for three weeks with triazolam but not loprazolam, a longer acting benzodiazepine, was associated with an increase in daytime "anxiety" in poor sleepers. ${ }^{13}$ This finding was replicated in a larger study in which triazolam, but not lormetazepam, increased anxiety compared with placebo. ${ }^{14}$

We agree with Jonas that these studies probably did not measure "pure" anxiety and that the clinical severity of the drug's effect is obscured both by the rating method and by the form of analysis. ${ }^{2}$ It is clear, however, from the clinical descriptions that many of the reactions with triazolam were of at least moderate severity and included anxiety, depression, and, in a few cases, psychosis. Kales and colleagues have observed similar results. ${ }^{7}$ In their studies the "anxiogenic" effect was limited to midazolam and triazolam, both with very short half lives.

Although Jonas argues that Oswald's data are flawed by multiple systematic biases and that the data of Kale's group are equally unreliable, independent support for an association between psychiatric disturbance and treatment with triazolam has come from two other sources. One controlled study found an increase in restlessness and anxiety during three weeks of treatment with low dose triazolam; ${ }^{15}$ another small placebo controlled study found more depressive symptoms with triazolam. ${ }^{16}$

Overall, then, most sources agree that rebound insomnia, amnesia, and psychiatric disturbance, although not unique to triazolam, are more often associated with its use than with other benzodiazepines. As always, in considering usefulness it is necessary to balance the benefits peculiar to a drug with its risks. In our opinion, there are numerous alternative treatments for insomnia available including benzodiazepines, non-benzodiazepines, and non-pharmacological methods; triazolam has no compelling singular benefits that outbalance its risks.

MICHAEL C O'DONOVAN MRC travelling fellow

Center for Cancer Research,

Massachusetts Institute of Technology,

77 Massachusetts Avenue, E17-536,

Cambridge, MA 02139, USA

PETER McGUFFIN

University of Wales College of Medicine, Professor of psychological medicine

Cardiff CF2 4XN

1 Kryzwicki KT. Safety of triazolam. Lancet 1991;338:632.

2 Jonas JM. Idiosyncratic side effects of short half-life benzodiazepine hypnotics: fact or fancy? Hum Psychopharmacol 1992; 7:205-16.

3 Wysowski DK, Barash D. Adverse behavioural reactions attributed to triazolam in the Food and Drug Administration's spontaneous reporting system. Arch Intern Med 1991;151:2003-8. 4 The sudden withdrawal of triazolam - reasons and consequences. Drug Ther Bull 1991;29:89-90.

5 Lader M, Lawson C. Sleep studies and rebound insomnia: methodological problems, laboratory findings and clinical implications. Clin Neuropharmacol 1987;10:291-312.

6 Kales A, Manfredi RL, Vgontzas AN, Bixler EO, Vela-Bueno A, Fee EC. Rebound insomnia after only brief and intermittent use of rapidly eliminated benzodiazepines. Clinical Trials and Therapeutics 1991;49:468-76.

Kales A, Soldatos CR, Bixler EO, Kales JD. Early morning insomnia with rapidly eliminated benzodiazepines. Science 1983;220:95-7.

8 Gillin JC, Spinweber GL, Johnson LC. Rebound insomnia: a critical review. $f$ Clin Psychopharmacol 1989;9:161-72.

9 Curren HV. Benzodiazepines, memory and mood: a review. Psychopharmacology 1991;105:1-8.

10 Greenblatt DJ, Harmatz JS, Englehardt N, Shader RI. Pharmacokinetic determinants of dynamic differences among three benzodiazepine hypnotics. Arch Gen Psychiatry 1989;46:326-32.

11 Scharf MB, Fletcher K, Graham JP. Comparative amnesic effects of benzodiazepine hypnotic agents. F Clin Psychiatry 1988;49:134-7.

12 Bixler EO, Kales A, Manfredi RL, Vgontzas AN, Tyso KL, Kales JD. Next day memory impairment with triazolam use. Lancet 1991;337:827-31.

13 Morgan K, Oswald I. Anxiety caused by a short-life hypnotic. BMF 1982;284:942.

14 Adam K, Oxwald I. Can a rapidly-eliminated hypnotic cause daytime anxiety? Pharmacopsychiatry 1989;2:115-9.

\title{
1966 revisited: bright new contract or brave old world?
}

\author{
General practice's attempt to regain the initiative
}

After several years of mauling by the government the General Medical Services Committee has picked itself up and returned to the ring. The discussion paper on the future of general practice produced by its chairman, Ian Bogle, and now endorsed by the committee, is a succinct and lucid attempt to regain the political initiative for the profession. ${ }^{12}$

It contains three basic arguments. Firstly, general practitioners can avoid the imposition of quality control only by conceding that bad practice exists and by promoting peer controlled reaccreditation and audit. Secondly, increasing managerial control of general practice is here to stay. Finally, the profession should accept the purchaser-provider split and negotiate a more favourable contract that emphasises quality of care.

Acceptance of quality of care as a central concern would represent the final defeat of the traditional defenders of general practice, coming as it does some 15 years after the Royal College of General Practitioners dared to speak of unacceptably low standards of practice, ${ }^{3}$ and nearly a decade after the triumphalism of General Practice: a British Success. ${ }^{4}$ Nevertheless, bad practice is hard to face and it is easier to find scapegoats-the few who are careless, incompetent, and even dangerous-than to accept that we are all "bad" at times. Variable quality care derives in part from professional isolation, from the rapid development of medical science itself, and from the fatigue of being on a treadmill.

General practitioners operate as franchisees, getting support from the franchiser, the NHS, but without losing autonomy and some element of personal risk. ${ }^{5}$ The 1966 family doctors charter increased the support and reduced the risk without compromising autonomy, and so proved both popular and successful. The 1990 contract reduced support, increased risk, and tightened control as the NHS management sought both to extend and to standardise the services provided by its franchisees. It is hardly surprising that it has been unpopular and stressful for general practitioners, ${ }^{6}$ but the logic of franchising makes further tightening of management control likely. ${ }^{7}$ 
Does the government need to compromise? To keep the political peace it may choose to do so, but other options are open to it, including encouragement for the partial privatisation of general practice, as with dentistry. The General Medical Services Committee may cherish the ostensible unity of general practice, but market logic drives us towards fragmentation and division, and the schisms within the profession described by Keighley in this issue ( $p$ 977) ${ }^{8}$ may fuel that process.

The provider friendly contract outlined by Ian Bogle emphasises the practice rather than the individual general practitioner as the provider and seeks to make delegation of work to other professionals more secure. It also dissects current workload into core general medical services (within normal working hours), out of hours services, and special services such as minor surgery, dispensing, and needs assessment for community care. ${ }^{1}$ Local negotiation would deal with local variations, and practices would be given a budget for services, staff, prescribing, and development. Quality control would be established through regular practice review and professional reaccreditation.

Would it work? It probably would in the shires, but perhaps not in the cities. Franchise general practice develops best when rising demand meets growing resources, ${ }^{9}$ but again it develops better in market towns than in urban areas. Resources are promised for general practice, but demand is already rising, partly for demographic reasons, ${ }^{10}$ but also because economic depression creates morbidity. ${ }^{11}$

With the proposed model the best practices with the most ambitious programmes for staff growth and service development will compete with their weary and lacklustre neighbours for resources from the same pool. It is difficult to see how the new proposals will eliminate variations in the quality of care. They may in fact exacerbate them, as weak practices become relative losers.

An alternative view identifies general practitioners' autonomy as the source of unacceptable variation in standards of care, ${ }^{12}$ and emphasises management, planning, and salaried general practice integrated into a broader primary care framework. ${ }^{13}$ In cities this approach may be more practicable than the traditional model of independent contractors and if adequately resourced may allow rapid improvement in service quality. The General Medical Services Committee might usefully take a pluralistic approach and develop a model for salaried practice.

General practice is on the defensive, but it still has several options for the future. The debate initiated by Bogle's controversial paper is necessary, and for the first time in 20 years of GMSC politics we cannot predict the outcome. Given general practitioners' longstanding hostility to control and the poor prospects for the economy and the NHS, the way forward for general practice looks long and difficult.

STEVE ILIFFE Senior clinical lecture

Department of Primary Health Care,

University College and Middlesex School of Medicine,

Whittington Hospital,

London N19 5NF

\footnotetext{
1 General Medical Services Committee. General practice: which way forward? A GMSC discussion document. London: General Medical Services Committee, 1993.

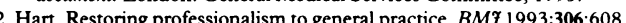

3 Royal College of General Practitioners. Evidence to the Royal Commission on the National Health Service J Royal Coll Gen Pract 1977:27:197-206.

4 General Medical Services Committee. General practice: a British success. London: General Medical Services Committee, 1983.

5 Iliffe $S$. Thinking through a salaried service for general practice. $B M F$ 1992;304: 1456-7.

6 Sutherland VJ, Cooper CL. Job stress, satisfaction and mental health among general practitioners before and after introduction of new contract. BMf 1992;304:1545-8.

Stanworth J, Smith B. Franchising for the small business. Oxford: Blackwell, 1991.

8 Keighley B. The RCGP revisited. BMF 1993;306:977-8.

Bosanquet N, Leese B. Family doctors and economic incentives. Aldershot: Dartmouth, 1989.

10 Frischer $\mathrm{M}$. Trends in morbidity and general practitioners' workload for middle-aged and elderly people from 1956 to 1982. I Public Health Med 1991;13:198-203.

1 Beale N, Nethercott S. Job loss and family morbidity: a study of factory closure. $f R$ Coll Gen Pract 1985;280:510-4.

2 Hart JT. A new kind of doctor. London: Merlin, 1988:157.

13 Medical Practitioners Union. The future of primary care. London: Medical Practitioners Union, 1992.
}

\title{
Where are we now with vaccines against AIDS?
}

\author{
Awaiting large scale trials of efficacy
}

Intense activity has been devoted to developing an effective vaccine for AIDS in the decade since HIV was identified as the causal agent. ${ }^{1}$ As in most scientific endeavours, there have been exciting advances, as well as setbacks and disappointments. Nevertheless, the results of extensive studies in experimental animal models and phase I and II clinical trials in humans provide some grounds for cautious optimism that effective vaccines against AIDS can be produced.

Simian immunodeficiency virus (SIV) induces in macaque monkeys a lethal disease indistinguishable from the disease induced by HIV in humans. In this model, over 200 monkeys have been protected by simple inactivated vaccines against infection with a lethal challenge dose of SIV. ${ }^{23}$ These inactivated vaccines protected against a wide range of antigenic types of SIV given intravenously and also against challenge by a mucosal route. ${ }^{45}$ The optimism generated by these early successes, was tempered, however, by the subsequent and totally unexpected discovery that most, if not all, of the protection observed was due to human $T$ cell antigens in the vaccines and challenge viruses and not to SIV components. ${ }^{6} \mathrm{~A}$ further sobering finding is that most attempts to protect macaques against SIV by using purified recombinant proteins derived from either the envelope or core of SIV have been unsuccessful even though some of these antigens stimulated good SIV neutralising antibody and cellular immune responses. $^{78}$

Nevertheless, there is evidence that macaques can be protected by immune responses to the virus. Passive transfer of antibody to SIV has convincingly been shown to prevent infection. ${ }^{9}$ Vaccination with live recombinant vaccinia virus expressing SIV envelope followed by purified gp 160 has been shown to protect against a biological clone of SIV that is genetically identical with the vaccine's composition. ${ }^{10}$ Most recently and most dramatically, vaccination with attenuated live SIV with a deletion in the regulatory nef gene protected against a challenge with 1000 monkey infectious doses of virus. " Thus data from the SIV macaque model indicate that viral antigens can induce protection but that the immunity induced by purified recombinant proteins is unlikely to extend to a wide range of antigenic types.

Studies in chimpanzees have so far been limited to the classic laboratory IIIB strain of HIV-1, which is unrepresentative of the strains circulating in the general population. Nevertheless, further encouraging results have emerged from 